furnaces and engines, but to obtain the same restult the cost of gas is greater than that of coal. Although the directors of the gas companies of the Metropolis are apparently not unwilling to advance the cause of smoke abatement, and thereby of public sanitation, by making a reduction in the price of gas used for trade purposes, they are prevented doing so by their Acts of Parliament. The Council are keeping the matter in view, and watching a favourable opportunity to urge the Government to grant the necessary powers.

Correspondence has been carried on on the subject of the gas stoves at the Bank of England, insisting on the necessity of fiues being provided to carry off the products of combution from all gas stoves used for warming purposes, and letters have been received thanking the Institution on behalf of the clerks for calling the attention of the Bank authorities to the matter. Voluminous correspondence has also been carried on with makers and inventors of stoves and smoke-prevention appliances, and of patent fuels, and with others, giving information and suggestions on points connected with the subject too various to be set out.

During the year several tests have been carried out by the Institution, and they have now under consideration the preparation of another volume of detailed reports of tests. The volume would include tests of various forms of furnaces, steam and other boilers, blow-pipe furnaces, smoke-preventing appliances, ventilating fans, non-conducting compositions, mechanical stokers, condensers, gas cooking and heating stoves, and various heating and cooking appliances using gas and coal as fuel.

The Council had at one time intended to exhibit at the Jarkes Museum typical forms of heating and smoke-abatement appliances, but for various reasons they considered it undesirable to carry out the scheme, and they propose instead to promote periodical exhibitions of special heating apparatus, or new methods of heating and smoke prevention, as opportunity may offer.

In connection with this branch of the subject, reference may be made to the exhibition of the Sanitary Institute held at I.eicester in September, at which various stoves and smokepreventing appliances were exhibited. Exhibitions of gas stoves for heating and cooking purposes have also been held in many of the chief provincial towns during the year.

A memorial, praying for a grant from the surplus funds of the International Health Exhibition, signed by the Duke of Westminster and other influential persons, was unavailing, although the object of this Institution so directly affects public health, the improvement of which was the avowed aim of the Health Exhibition. This is much to be regretted, as the lack of funds not only militated against the general operations of the Institution, but it prevented the Council establishing a testing department, which is a necessary adjunct to the Institution for the advancement of its objects.

During the year a lecture given in the Parkes Museum by Mr. T. Fletcher, of Warrington, on Smoke Abatement, and a pamphlet containing three prize essays on the same subject, have been printed by the Institution and circulated. A paper by Mr. W. R. E. Coles, on the Hygienic, Moral, and Economic Aspects of the Smoke Question, read at the Leicester Congress of the Sanitary Institute, is now being prepared for circulation.

$$
\begin{gathered}
\text { By order, } \\
\text { E. White Walis, } \\
\text { Secretary }
\end{gathered}
$$

\section{THE WINGS OF BIRDS}

THE power of flying through the air is one of the principal characteristics of the class of birds. Although some nembers of the other great divisions of the Vertebrates-the bats among Mammals, the extinct pterodactyle among Reptiles, the flying-fishes among Pisces-possess this power in a greater or less degree, these are all exceptional forms, whereas in birds the faculty of flight is the rule, its absence the exception. Among Invertebrates this power is possessed in a very complete degree by the greater number of insects.

In the normal structure of the vertebrate animals there are two pairs of limbs, anterior and posterior, never more. It often happens, however, that one pair, and sometimes both, are suppressed, being rudimentary, functionless, or entirely absent. Flight is always performed by the anterior or pectoral pair, more or less modified for the purpose. The super-addition of

' Abstract of Lecture by Prof. W. H. Flower, LL.D., F.R.S., at the Royal Institution. February 19,1986 . wings to arms, as in the pictorial representations of angels, has no counterpart in nature. The wings of the bird, the bat, the pterodactyle, and flying-fish, are the homologues of the arms of man, the fore-legs of beasts. In the flying-fish the power is gained simply by an enlargement of the pectoral fin, and the function is very imperfect; in the pterodactyle, by immense elongation of one (the outer) finger, and extension of the skin between it and the side of the body; in the bats, by elongation of the four outer fingers, and extension of a web of skin between them and the body. In the bird the flying organ is constructed mainly of iepidermic structures, peculiar outgrowths from the surface, called feathers-modifications of the same tissue which constitutes the hair, horns, scales, or nails of other animals. Feathers are met with only in birds, and are found in all the existing members of the c'ass, constituting the general covering of the surface of the hody.

The framework to which the broad expanse formed by the feathers is attached is composed of hones, essentially resembling those of the fore-limb of other Vcrtebrates. 'The distal segment, manus, or hand, in the vast majority of birds, has three metacarpal bones and digits, the former being more or less united together in the adult state. The digits appear to correspond with the pollex, index, and medius of the typical pentadactyle manus; the second is always the longest. Both it and the pollex frequently bear small horny claws at their extremity, concealed among the feathers and functionless, but very significant in relation to the probable original condition of the avian wing. These claws are altogether distinct from the large, and often functional, spurs developed in many species from the edge of the metacarpal bones, resembling bo $h$ in use and situation the corresponding weapons in the hind-feet. The third digit dues not bear a second phalanx or claw in any existing bird.

The quills, remiges, or flight-feathers attached to the bones of the manus (called "primaries"), never exceed twelve in number, and are (as has been recently shown by Mr. Wray) in the very great majority of birds distributed as follows :-Six, or in some few cases (flamingo, storks, grebes, \&c.), seven to the metilcarpus; of the remainder or digital feathers, one (ad-digital) is attached close to the metacarpo-phalangeal articulation, and rests on the phalanx of the third digit; two (mid-digital) have their bases attached to the broad dorsal surface of the basal phalanx of the second digit, which is grooved to receive them ; the remainder (prce-dirital) are attached to the second phalanx of the same digit. These last vary greatly in development, in fact their variations constitute the most important structural differences of the wing. In most birds there are two; the proximal one well developed, the distal always rudimentary; but the former may show every degree of shortening, until it becomes quite rudimentary, or even altogether absent, as in Fringillicia and other "nine-primaried" birds, in which there are six metacarpal remiges, one ad-digital, two mid-digital, and no præ-digitals, or only a very rudimentary one. The smaller feathers at the base of the quills, called upper and under covert:, have an equally regular arrangement. The webs or vanes of all the flightfeathers aré made up of a series of parallel "barbs" which cohere together by means of minute hooklets, and so present a continuous, solid, resisting surface to the air.

Such is the characteristic structure of the wing in almost all carinate birds, whether powerfully developed for flight, as in the eagles, albatrosses, or swifts, or whether reduced in size and power to practically useless organs, as in the extinct great auk, the dodo and its kindred, weka rail, notornis, cnemiornis, \&c., most of which, being inhabitants of islands containing $\mathrm{n}$. destructive land mammals, appear to have lost the principal inducement, and with it the power, to fly.

In the penguins (Spheniscomorpha) the feathery covering of the wing entirely departs from the normal type. Each feather is like a flattened scale frayed out at the edges, the barbs are non-coherent and have no hooklets. They form an imbricated covering of both surfaces of the wing, including the broad patagium which extends from the cubital side of the limb, but appear to have no definite relation to the bones, and cannot be divided into distinct groups, corresponding to those described above. The structure of the wing separates the penguins sharply from all the other carinate birds.

The Ratitæ, or birds without keel to the sternum, form another very distinct group, distinguished by the rudimentary or imperfect condition of the remiges or quills, which never have coherent barbs, and are therefore unfitted to the purpose of flight. In the ostrich and rhea the bones, though comparatively 
small, are distinct and c mplete, and the feathers large and definitely arranged. The emu, cassowary, and apteryx show various degrees of degeneration, which apparently culminated in the dinornis, no trace of a wing-bone of which bird has ever been found. The question which naturally presents itself with regard to these birds is, whether they represent a stige through which all have passed before acquiring perfect wings, or whether they are descendants of birds which had once such wings, but which have become degraded by want of use. In the absence of palæontological evidence it is difficult to decide this point. The complete structure of the bony framework of the ostrich's wing, with its two distinct claws, rather points to its direct descent from the reptilian hand, without ever having passed through the stage of a flying organ. The function of locsmotion being entirely performed by powerfully developed hind-legs, and the beak mounted on the long flexible neck being sufficient for the offices commonly performed by hands, the fore-limbs appear to have degenerated or disappeared, just as the hind-limbs of the whales disappeared when their locomotory functions were transferred to the tail. This view is strengthened by the great light that has been thrown on the origin of the wings of the flying birds by the fortunate discovery of the Archaoptery' $x$ of the Solenhofen beds of Jurassic age, as in this most remarkable animal, half lizard and half bird, the process of modification from hand to perfect flying bird is clearly demunstrated. The three digits which in the existing forms are more or le s pre sed together and imperfect, still retain their freedom and complete number of phalanges, and are each armed with terminal claws, while the flight feathers and remiges of the cubital, metacarpal, and digital series are fully developed and evidently functional. The earlier stages in which the outer digits were still present, and the feathers imperfectly formed or merely altered scales, are not yet in evidence.

Some conception of the process by which a win s may have been formed may also be derived from the study of the urowth of feathers on the feet of some domestic varieties of pigeons and poultry, illustrations of which were shown at the lecture.

\section{THE SUN AND STARS 1} VII.

$W^{E}$ have now to endeavour to apply to the more distant stars some of the facts which I have brought before you touching the nearest one-our sun. What we have to do in the short time at our disposal is to choose those facts which will give us the greatest amount of knowledge concerning the greatest number of those stars.

When the star that is nearest to us has set, the number of stars which a pair of eyes can see on a dark night, whether they happen to be north of the equator or south of it--for the number of stars is pretty equally distributed north and south-is something under 3000 . But when we leave behind us the power of the unaided eye, and consider what re ults can be obtained by the optical means now at man's disposal, we have to increase these 6000 to something like forty or fifty millions, so that, if we can by any chance obtain facts touching one star that are applicable to others, we do a great deal. We a-e, in fact, dealing with 50,000 , 000 bodies instead of one.

The first thing regarding these distant bodies to which $I$ have to draw attention is that they have been divided for purposes of convenience-astronomical and other-into magnitudes such that the first magnitude means the brightest star we can see; and so we go on till now we go down to the sixteenth magnitude.

The order of diminution of brightness is not quite exact from the first magnitude to the faintest visible to the naked eye, but it may be taken on the average to be about two-fifths. If we take this ratio as the normal one down to the sixteenth magnitude we get the following values nearly :-

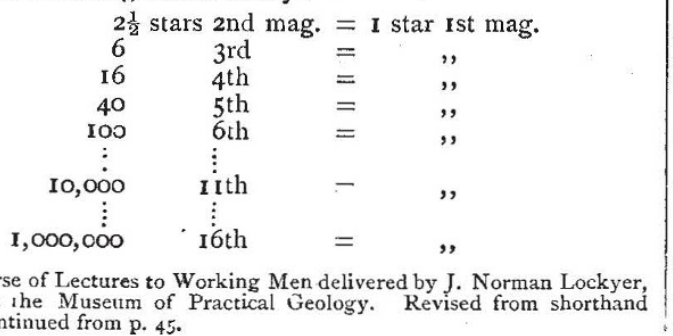

${ }^{1}$ A Course of Lectures to Working Men delivered by J. Norman Lockyer,
F.R.S., at the Museum of Practical Geology. Revised from shorthand notes. Continued from p. 45
We not only get the stars thus visible, but, as they can be photographed in a certain period of time, this period measures their photographic brightness. We find, for instance, that a first magnitude star can be photographed in the three-thousandth part of a second; that a star of the seventh magnitude can be photographed in about one second ; and when we come to the twelfth magnitude we must turn seconds into minutes, and we shall require two of them to get an impression on the plate; till, working on gradually to the sixteenth magnitude, we find that the photographic plate, which requires only the three-thousandth part of a second for a star of the first magnitude, requires one hour and twenty-three minutes (or eighty-three minutes) to receive the impression, we find the ratio of two-and-a-half times to be practically indicated by the times of exposure.

The relative photographic light of stars of all magnitudes when the most rapid dry plates are used is shown in the following table :-

\begin{tabular}{|c|c|c|c|c|c|c|c|}
\hline \multirow{2}{*}{\multicolumn{6}{|c|}{ Magnitude }} & \multicolumn{2}{|c|}{ Time of exposure } \\
\hline & & & & & & & \\
\hline Ist & $\cdots$ & $\ldots$ & $\ldots$ & $\ldots$ & $\ldots$ & & 0.005 \\
\hline 2nd & $\cdots$ & $\ldots$ & $\ldots$ & $\ldots$ & $\ldots$ & & $0^{\circ} \mathrm{CI}_{3}$ \\
\hline $3^{\text {rd }}$ & $\ldots$ & $\ldots$ & $\ldots$ & $\ldots$ & $\ldots$ & & 0.03 \\
\hline $4^{\text {th }}$ & $\ldots$ & $\ldots$ & $\ldots$ & $\ldots$ & $\ldots$ & & 0.08 \\
\hline $5^{\text {th }}$ & $\cdots$ & $\cdots$ & $\cdots$ & $\cdots$ & $\cdots$ & & 0.2 \\
\hline 6th & $\ldots$ & $\cdots$ & $\ldots$ & $\cdots$ & $\cdots$ & & 0.5 \\
\hline 7 th & $\cdots$ & $\cdots$ & $\cdots$ & $\cdots$ & $\cdots$ & & I. 3 \\
\hline 8 th & $\cdots$ & $\ldots$ & $\ldots$ & $\ldots$ & $\ldots$ & & $3^{\circ} \circ$ \\
\hline 9th & $\ldots$ & $\cdots$ & $\cdots$ & $\cdots$ & $\ldots$ & & 8.0 \\
\hline roth & $\cdots$ & $\cdots$ & $\ldots$ & $\ldots$ & $\ldots$ & & $20 \%$ \\
\hline I Ith & $\ldots$ & $\cdots$ & $\ldots$ & $\cdots$ & $\ldots$ & & $50^{\circ} 0$ \\
\hline I 2th & $\ldots$ & $\ldots$ & $\ldots$ & $\ldots$ & $\ldots$ & $2 \%$ & \\
\hline $13^{\text {th }}$ & $\ldots$ & $\cdots$ & $\ldots$ & $\cdots$ & $\ldots$ & $5^{\circ} \mathrm{O}$ & \\
\hline I $4^{\text {th }}$ & $\cdots$ & $\ldots$ & $\ldots$ & $\ldots$ & $\ldots$ & 13.0 & \\
\hline I $5^{\text {th }}$ & $\ldots$ & $\ldots$ & $\ldots$ & $\ldots$ & $\ldots$ & $33^{\circ} \circ$ & \\
\hline I6th & $\cdots$ & $\cdots$ & $\cdots$ & $\cdots$ & $\cdots$ & $83^{\circ} \circ$ & \\
\hline
\end{tabular}

We must not for one moment imagine that, because for many reasons it has been necessary to divide stars into magnitudes, all the stars are of exactly the same size at different distances, or of different sizes at the same distance. We hnow very little at present relatively. But this we do know, every new fact has shown us that some of the apparently fainter stars may be very large, and some of apparently the brightest stars may be small. You can understand that the light which we get from the stars will depend upon these two things. Take the case of the sun for instance. We know that the sun is a small star, and yet it gives us a great deal of light because it is near to us. We know that some of the other stars are very distant, and they give us a small amount of light, not because they are small, but because they are so far away.

We are living now in a very interesting time, because people are beginning to work here and there, not in too many places, to get the stars to write their own antobiography, so to speak. In fact, a very important attempt is being made at the present moment to replace observations of the positions of the stars by actual photographs. Observations, you know, being human, are always liable to error. This plate, which I am about to show you, is a photograph that $I$ bave received from the Brothers Henry of Paris only this morning, showing what photography can do in registering the exact positions and brightnesses of an almost innumerable army of stars by simply exposing a plate in a telescope.

If it is wished to obtain photographs of stars of the sixteenth magnitude, the plate will have to be exposed eighty-three minutes. If we are content to get stars of the seventh magnitude, then two minutes will be enough.

All the stars that you see here are visible in a very restricted portion of the sky in the constellation Cygnus, not very far from the Milky Way. You can understand what a happy thing it will be for the astronomer of the future if, when he wants to know the state of the heavens in this nineteenth century, in. stead of having to consult musty books of observations which may probably be wrong, he can refer to a book of which the leaves are made of glass, and on which is recorded the attobiography of every square degree of the heavens as you see on this diagram before you.

In our attempt to apply to these other bodies the knowledse which we have acquired touching the sun, of course we have to consider chiefly the light sent to us by them. You will see in a moment that if the sun were very much farther away from us than it really is-imagine it for a moment so far away that 